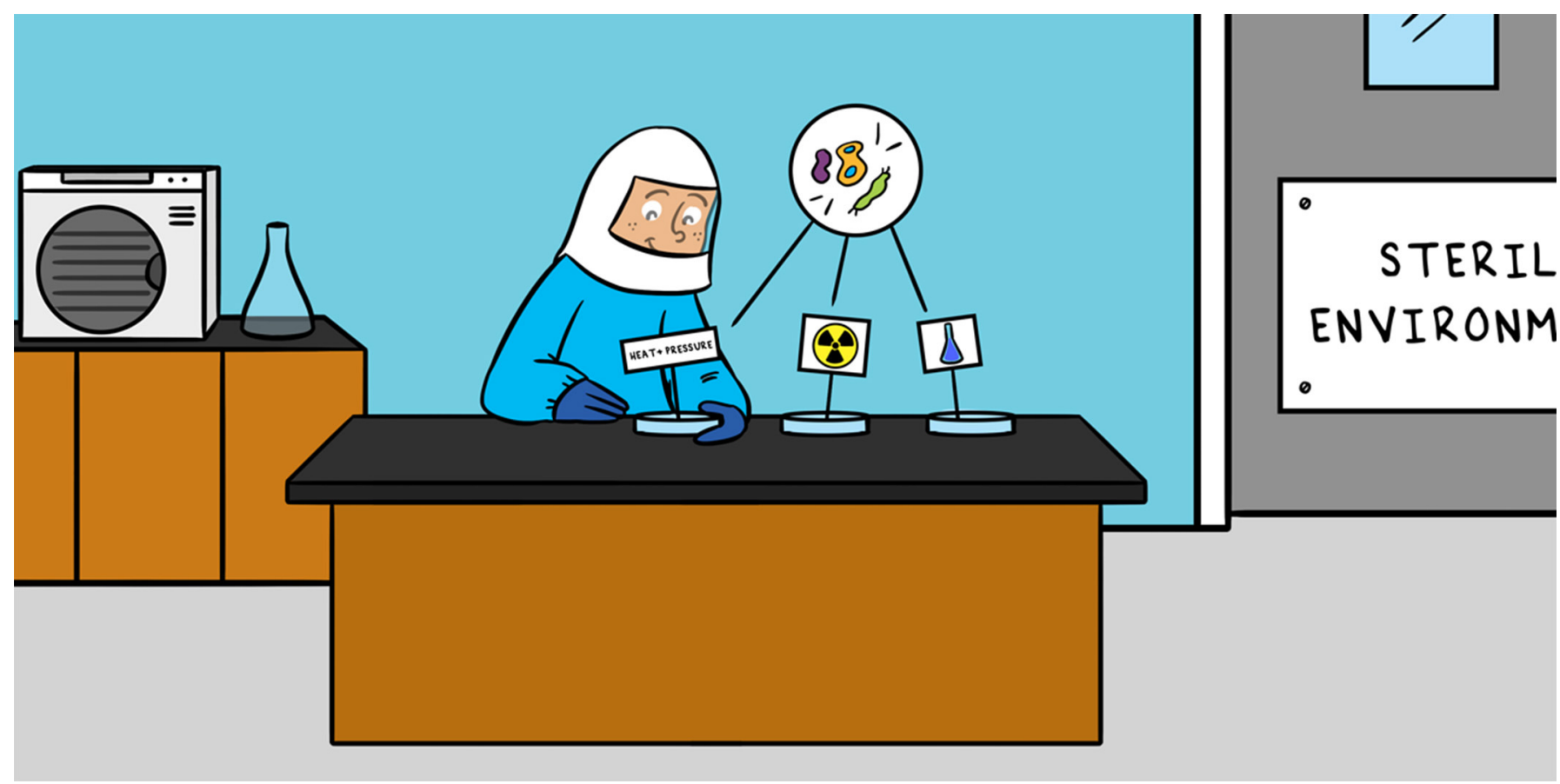

\title{
THE TRUE SUPERHEROES: MICROORGANISMS SURVIVE IT ALL!
}

Julia M. Otte ${ }^{1,2,3^{* t}}$ and Katja Laufer-Meiser ${ }^{3 t}$

${ }^{1}$ Deep-Sea Ecology and Technology, Alfred Wegener Institute, Helmholtz Center for Polar and Marine Research, Bremerhaven, Germany

${ }^{2}$ Deep-Sea Ecology and Technology, Max Planck Institute for Marine Microbiology, Bremen, Germany

${ }^{3}$ Center for Applied Geoscience, Geomicrobiology, University of Tübingen, Tübingen, Germany

YOUNG REVIEWERS:

LICEO

COCCHETTI

AGE: 15
Did you know that microorganisms can live far up in the clouds and deep in the Earth's crust? These tiny organisms have adapted to all special habitats on Earth. To study special habitats, scientists can focus on the microorganisms and their biological reactions, or on the non-living components, like minerals and chemical reactions. However, it can be difficult to separate the two! Since little was known about the best way to remove microorganisms from environmental samples without changing the non-living properties of the sample, we decided to perform an experiment to find out. We exposed marine sediments to three different methods of sterilization, to see which method was best for eliminating microorganisms. We also studied whether the three methods affected the chemical properties of our samples. We found that it is challenging to create sterile conditions because some microorganisms can survive high pressure, high temperature, radiation, and toxic chemicals! 


\section{METABOLISM}

All the biochemical processes that maintain the life of an organism. In simple words, metabolism is the sum of eating, drinking, digesting, and growing

DORMANCY

When microorganisms shut down their metabolism, which means when they take a deep sleep and their growth, development and physical activity are temporarily stopped.

\section{SPORE}

A state in which microorganisms can survive long times under harsh conditions. Microorganisms create a special blanket around them which is similar to a plant seed.

\section{NUCLEIC ACIDS}

Complex molecules that store genetic information. The two types of nucleic acids are DNA and RNA. DNA shows the presence of microorganisms and RNA can show if they are active.

\section{MICROORGANISMS CAN LIVE EVERYWHERE!}

Microorganisms were the earliest life forms on our planet. They are also the smallest! The term "microorganisms" describes a diverse group of single-celled organisms including bacteria, archaea, some fungi, algae, protozoa, and viruses. These organisms can only be observed using microscopes because of their tiny size. Microorganisms live in our stomachs and on our skin, but they also live everywhere else-from the deepest parts of the Earth's crust to high up in the clouds. Some even live under the ice of the Antarctic, or in 3.5 billion-year-old volcanic rocks, or in hot springs (Figure 1A). They can be found at extreme temperatures, both hot and cold, in the extreme salinity of the Dead Sea, in the extreme radiation of nuclear reactors, under the high pressures of the deep sea, in the complete dryness of desserts, and in acidic and basic lakes. Although many of these extreme conditions are toxic to most other life forms, bacteria have evolved ways to resist the harsh conditions and survive.

\section{SURVIVAL SECRETS OF MICROORGANISMS LIVING UNDER EXTREME CONDITIONS}

Microorganisms have evolved several fascinating strategies to help them survive in extreme habitats (Figure 1B). Here, we explain a few of them.

\section{Metabolic Flexibility}

Many microbes have evolved the ability to change which foods they eat, depending on what is available. Some can also adapt their metabolism to changing conditions, like heat or cold [1].

\section{Dormancy}

When conditions are unfavorable, some microorganisms can enter a state of dormancy, which resembles "sleep mode." They slow down their metabolism so that they eat and grow less until conditions become favorable again.

\section{Spores}

When conditions are unfavorable, some microorganisms can form a special blanket around themselves, made of extraordinary proteins. These protected forms are called spores. Spores can help a microorganism survive for thousands of years in harsh conditions!

\section{Repair Mechanisms}

Extreme conditions can damage the genetic material of microorganisms. The genetic material includes DNA and RNA, which are called nucleic acids. Some microorganisms have evolved special repair mechanisms to fix nucleic acid damage. 
Figure 1

(A) Microorganisms can survive everywhere on our planet, even in places with extreme conditions like the Earth deep crust with almost no water and a lot of pressure and in environments previously thought to be completely sterile like the NASA clean room which is the cleanest room on our Planet but contains also traces of microbes. (B) Microorganisms living in extreme environments have evolved several fascinating survival strategies.

\section{A) Microorganisms live everywhere on our Planet!}

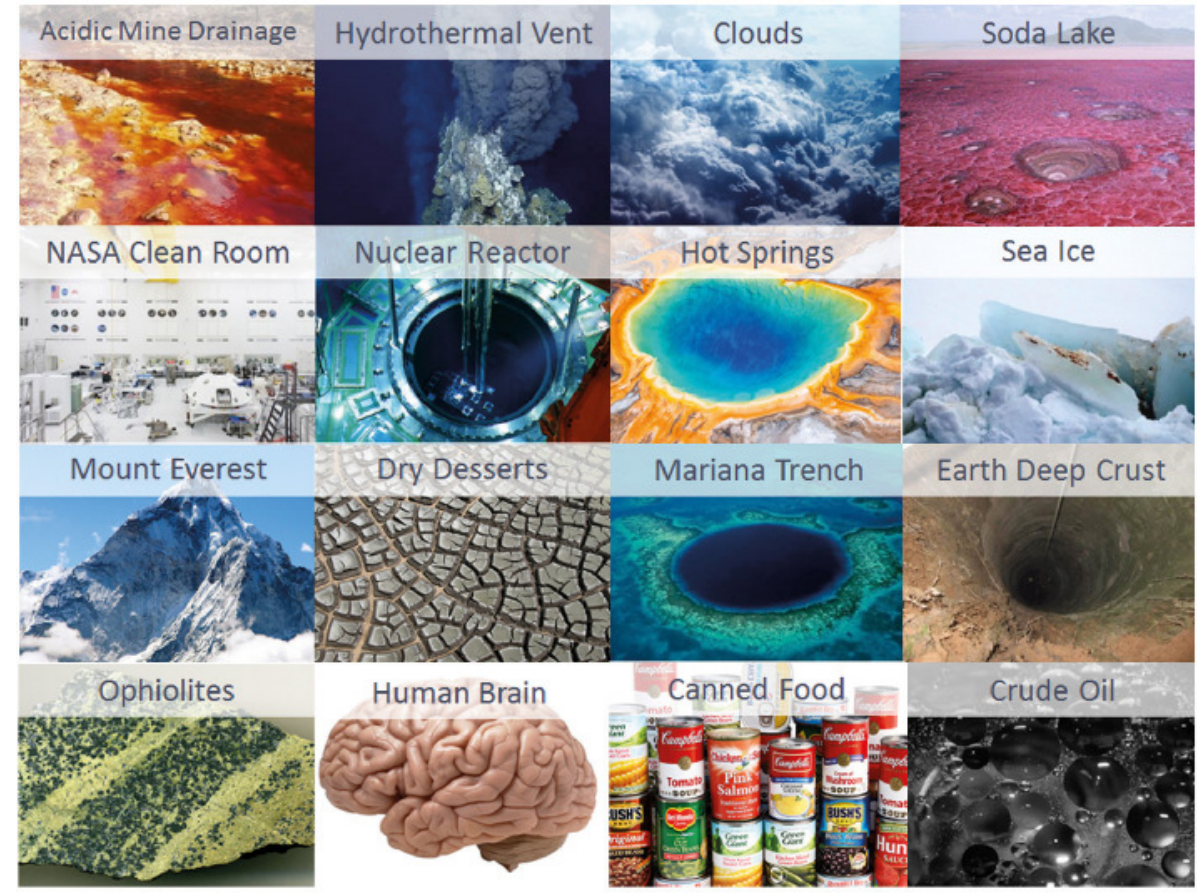

\section{B) General survival strategies of microorganisms in special habitats}
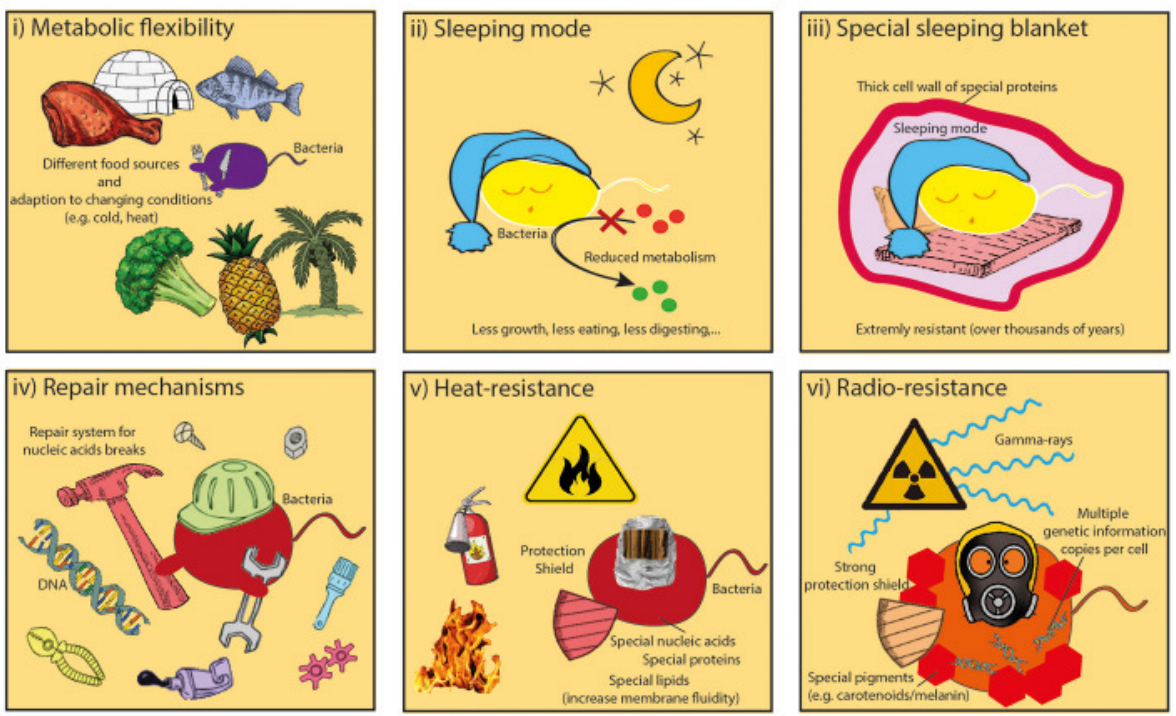

Figure 1

\section{Heat Resistance}

Some microorganisms have special proteins and lipids that can protect them from very high temperatures. The Greek prefixes thermo- and pyro- tell us that these thermo- and pyro-microorganisms can live close to heat and fire.

\section{Radio-Resistance}

Gamma-rays are a type of radiation produced by the decay of radioactive material. Because gamma-rays can penetrate tissues and cells, they are very dangerous for most organisms. Some 
BIOLOGICAL

PROCESSES

All processes that are performed by

living organisms

\section{GEOCHEMICAL}

PROCESSES

All processes that happen in the environment that are purely driven by chemical reactions.

\section{STERILIZATION}

A process that kills, removes, or deactivates microorganisms. microorganisms produce extraordinary pigments that serve as a protective shield against gamma-rays. These radiation-resistant microorganisms also contain multiple copies of their genetic information, which helps them to survive if one copy is damaged by radiation.

\section{WHAT IS THE BEST WAY TO KILL MICROORGANISMS?}

Microorganisms have a huge impact on our environment-they make life on Earth possible. Most microbial habitats have not been well-studied yet. For example, $95 \%$ of the ocean is still not well-characterized. This means that researchers who explore marine habitats still have a lot of work to do! When researchers study samples from the environment, they often want to know whether the processes happening in those samples are biological processes, meaning that they are driven by the biological activity of living microorganisms, or whether they are geochemical processes, meaning they are driven by abiotic, chemical reactions, without the activity of living organisms (Figure 2A). One way to know which kinds of processes are occurring is to eliminate all microorganisms from the environmental samples so that the geochemical processes can be studied on their own. Eliminating all microorganisms from a sample is called sterilization (Figure 2B) [2].

To effectively investigate geochemical processes, the sterilization methods used on the samples should not affect the geochemical processes. Before our experiment, not much was known about whether sterilization methods change the geochemical properties of environmental samples. So, we decided to study the effects of commonly used sterilization techniques on marine sediment. We soon found out that this question was not as straightforward as it seems!

\section{HOW CAN WE PROVE THAT AN ENVIRONMENTAL SAMPLE IS STERILE?}

What does "sterile" mean, exactly? By definition, it means that something is totally clean and free of living microorganisms. When we want to remove microorganisms from our experimental samples, we must think about how we will test for the presence of microorganisms. How do we know if the microorganisms are living? Well-known properties of living cells include an organized cell structure, an intact cell membrane, the ability to respond to stimuli like chemicals or light, and the ability to grow and reproduce. We can easily measure some of these properties in the lab (Figure 2C). We can examine the reproduction of microorganisms by counting the number of living cells under a microscope or by growing them in dishes called agar plates, which contain nutrient-rich food. We can examine 
Figure 2

(A) In environmental sediments are biological processes mediated by e.g., microorganisms and geochemical processes by chemicals.

(B) Scientists sterilize environmental samples to study the chemical properties of the sample without interference from the biological reactions of microorganisms. Methods of sterilization include autoclaving, radiation with gamma-rays, or treatment with toxic chemicals. (C) The effectiveness of sterilization methods can be assessed by measuring biological factors, such as growth of microorganisms on agar plates, productivity (consuming food like amino acids, digesting, and forming biomass), and the presence of nucleic acids. Sterilization can also affect the geochemical properties of the sample, causing minerals in the sample to change or causing the release of certain substances.

\section{AUTOCLAVE}

An instrument that applies heat and pressure and is used to kill microorganisms.

\section{A) Why do scientists sterilize environmental samples?}

Complex environmental sample

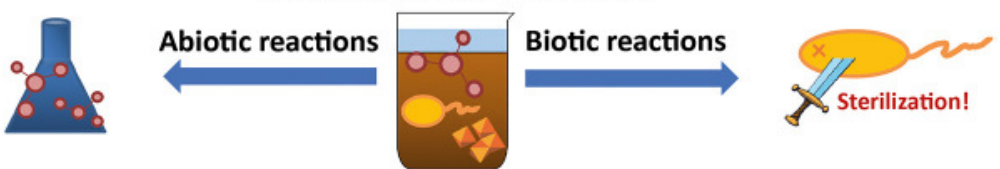

\section{B) Standard sterilization methods for environmental studies}

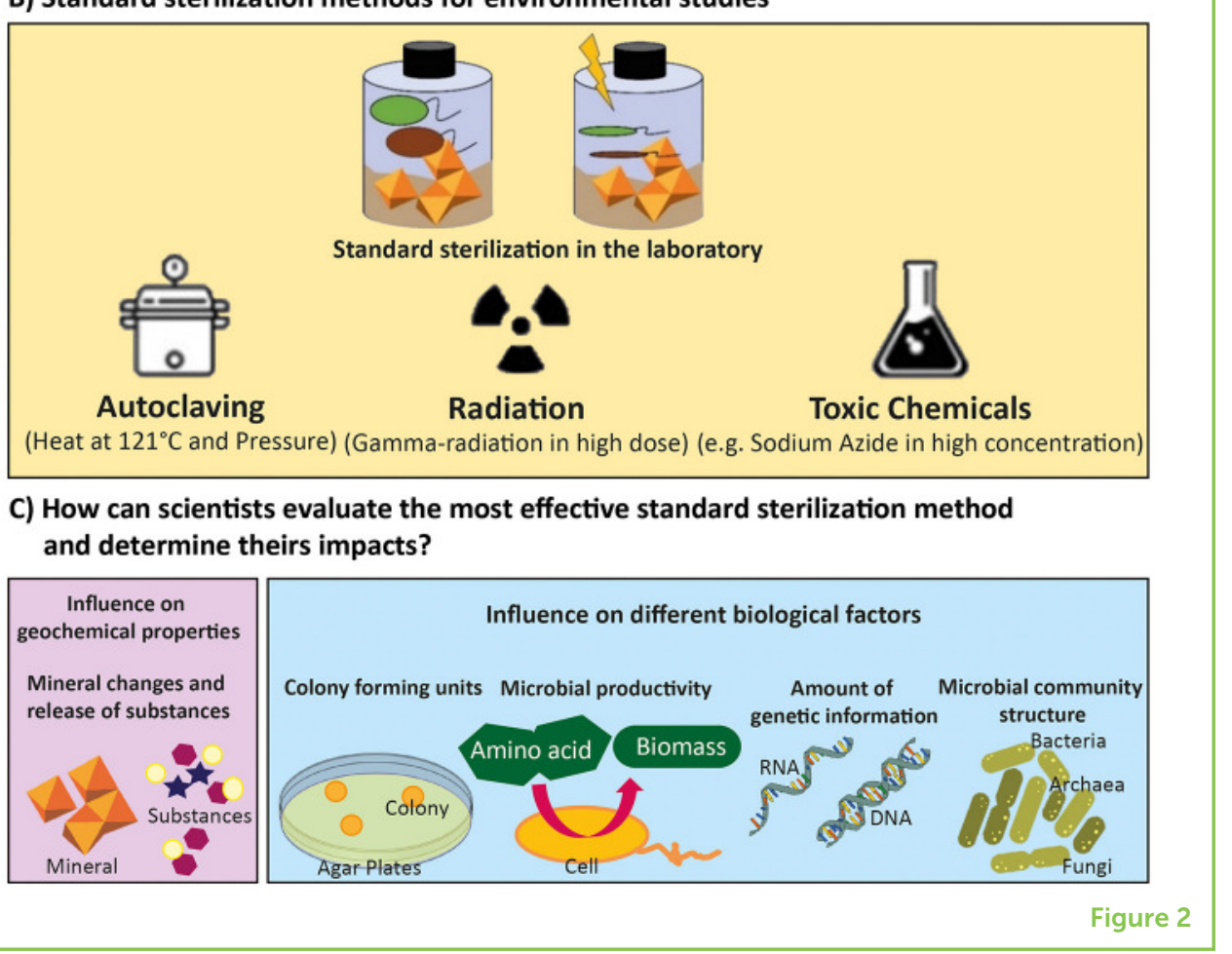

microbial productivity, which means following microbial activity in the laboratory, by quantifying how much the microorganisms are eating, digesting, and producing. For example, we can measure how many amino acids microorganisms eat while producing biomass to grow. There are also laboratory techniques to measure the amounts of nucleic acids (RNA and DNA) in a sample providing information about the present microbial community and which microorganisms are active.

\section{OUR STUDY WITH MARINE SEDIMENT}

To determine the most effective method to sterilize marine sediment samples, we looked at the impacts of different sterilization methods on marine sediment. Equipped with rubber boots, shovels, gloves, and buckets, our research team collected marine sediments in Denmark, on the Baltic Sea coast. We sterilized these samples using three methods: autoclaving, in which samples were exposed to high heat $\left(121^{\circ} \mathrm{C}\right)$ and high pressure; a high dose of gamma-radiation; or a high concentration of a toxic chemical called sodium azide (Figure 2B) [2]. 
After the sterilization treatments, we looked for the presence of microorganisms in the samples by directly counting them on agar plates, detecting how much they were growing, and measuring the amounts of nucleic acids present. We took these measurements right after sterilization and again 2 weeks later. At the same time points, we assessed the geochemical properties of the samples, to see if substances were released from the samples or if changes to the minerals occurred due to the sterilization processes (Figure 2C).

\section{NUCLEIC ACIDS ARE STILL PRESENT IN STERILIZED SAMPLES!}

Surprisingly, we still found nucleic acids immediately after all sterilization procedures (Figure 3A) [2]. So far, it is known that DNA from dead microorganisms can persist in ocean sediments for weeks to years [3]. RNA is normally found primarily in living microbial communities, but there are hints that RNA also persists long after the death of the organisms, and that RNA might be more stable in ocean sediments than previously assumed [3]. Nucleic acids can be broken down by special proteins called enzymes, which work like molecular scissors. After sterilization by autoclaving, we knew that DNA-cutting enzymes were still working because the amount of DNA was reduced after 2 weeks. Chemicals like sodium azide do not affect most nucleic acid-cutting enzymes, which is illustrated by the degradation of DNA and RNA at the 2 week time point in those samples. In gamma-irradiated samples, however, low levels of RNA were still present after 2 weeks. It is possible that the RNA-cutting enzymes were damaged by the radiation and no longer able to degrade the RNA. Does the presence of nucleic acids mean that the samples are sterile, or not?

\section{MICROORGANISMS SURVIVED, MINERALS CHANGED, SUBSTANCES WERE RELEASED}

Autoclaving is widely used for sterilization because it inactivates most fungi and protozoans. But a lot of bacteria and archaea survived autoclaving in our experiment (Figure 3A) [2]. In addition, autoclaving changed the minerals in our sediment samples and caused the release of different kinds of substances from the samples. Sterilization by gamma-radiation eliminated most microorganisms, but it also caused the release of substances from our sediment samples and changed minerals (Figure 3A) [2]. Therefore, autoclaving and radiation might not be the best sterilization methods to use for environmental samples, since they changed the sample's geochemical properties. Sodium azide sterilization killed only a minority of microorganisms but inhibited microbial growth by the two-week time point [2, 4]. Sodium azide did not change the release of substances from our samples or the minerals in those samples. 
Figure 3

(A) Common

sterilization techniques were investigated to determine their effects on environmental samples and microorganisms.

Autoclaving was best at removing all traces of microorganisms, and sodium azide was worst. However autoclaving caused the most changes to the environmental sample, particularly 2 weeks after sterilization. (B) Microorganisms have special "knight's armor" that helps them to survive everything, including high temperatures, a high doses of gamma-rays, and high

concentrations of chemicals. From other studies, we know microorganisms can also survive at low and high $\mathrm{pH}$, under

pressure, in a vacuum, under UV light, in high salinity, and in many other harsh conditions.

\section{A) Overview of study results using typical standard sterilization methods}

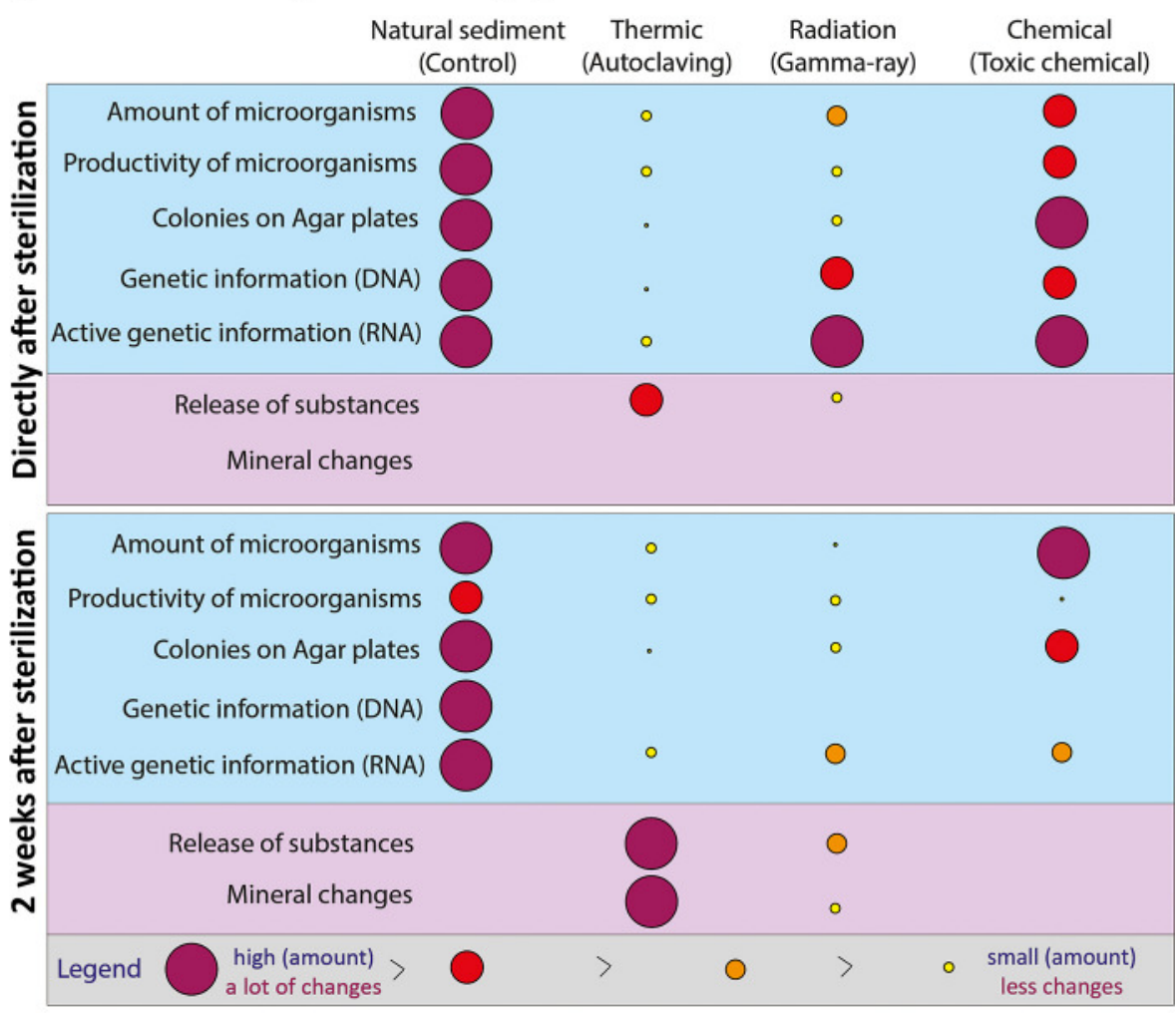

B) Microorganisms can survive everything!

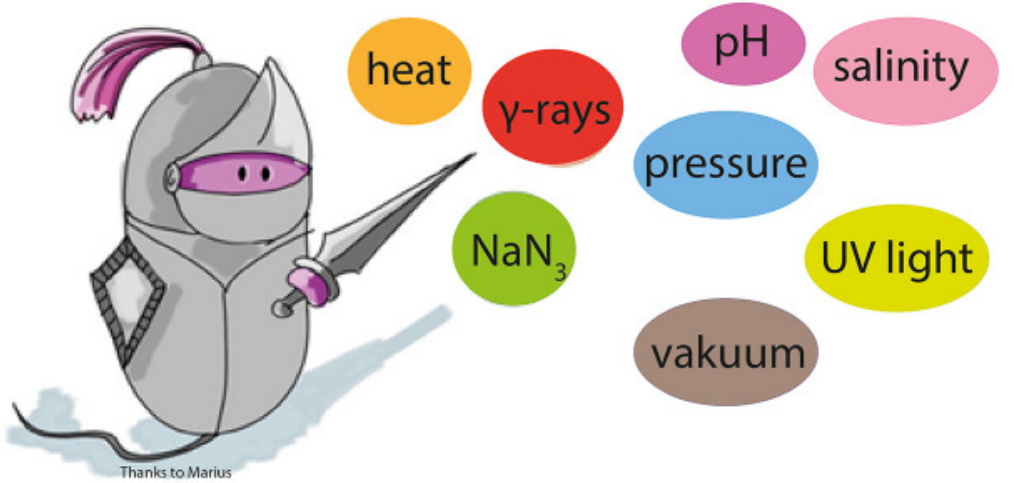

Figure 3

To clearly distinguish biological processes from geochemical processes in environmental samples, an optimal sterilization method must be chosen. However, all methods seem to have disadvantages, so researchers need to compromise depending on the research questions to be answered. Autoclaving should be used for studies that focus on biological properties, while chemicals and gamma-radiation might be better to sterilize samples that will be analyzed for geochemical properties. 
Our experiments make it clear that microorganisms are unseen heroes, much stronger than we think (Figure 3B)! While their survival skills are truly amazing, these skills make it difficult for scientists to study the geochemical properties of marine sediments or other habitats. Since microorganisms can survive virtually every challenging condition they face, including high temperature, extreme pressure, strong radiation, and toxic chemicals, it can be difficult to truly remove all traces of them from environmental samples. It is also challenging to choose the proper sterilization methods because some methods can affect the geochemical properties of samples, too. Our results demonstrate that living things, particularly microorganisms, are intimately interconnected with their environments. Microorganisms and their environments constantly affect each other in complicated ways that make it possible for life to exist on Earth!

\section{ORIGINAL SOURCE ARTICLE}

Otte, J. M., Blackwell, N., Soos, V., Rughöft, S., Maisch, M., Kappler, K., et al. 2018. Sterilization impacts on marine sediment - are we able to inactivate microorganisms in environmental samples? FEMS Microbiol. Ecol. 94:12. doi: 10.1093/femsec/fiy189

\section{REFERENCES}

1. Otte, J. M., Harter, J., Laufer, K., Blackwell, N., Kappler, A., and Kleindienst, S. 2018. The distribution of active iron cycling bacteria in marine and freshwater sediments is decoupled from geochemical gradients. Environ. Microbiol. 20:2483-99. doi: 10.1111/1462-2920.14260

2. Otte, J. M., Blackwell, N., Soos, V., Rughöft, S., Maisch, M., Kappler, K., et al. 2018. Sterilization impacts on marine sediment - are we able to inactivate microorganisms in environmental samples? FEMS Microbiol. Ecol. 94:12. doi: 10.1093/femsec/fiy189

3. Torti, A., Lever, M. A., and Jørgensen, B. B. 2015. Origin, dynamics, and implications of extracellular DNA pools in marine sediments. Mar. Genomics 24:185-96. doi: 10.1016/j.margen.2015.08.007

4. Bore, K. E., Apostel, C., Halicki, S., Kuzyakov, Y., and Dippold, M. A. 2017. Soil microorganisms can overcome respiration inhibition by coupling intra- and extracellular metabolism: $13 \mathrm{C}$ metabolic tracing reveals the mechanisms. ISME J. 6:1423-33. doi: 10.1038/ismej.2017.3

SUBMITTED: 29 May 2020; ACCEPTED: 04 August 2021; PUBLISHED ONLINE: 30 August 2021.

EDITED BY: Gianpiero Vigani, University of Turin, Italy

CITATION: Otte JM and Laufer-Meiser K (2021) The True Superheroes: Microorganisms Survive it All! Front. Young Minds 9:567078. doi: 10.3389/frym. 2021.567078 


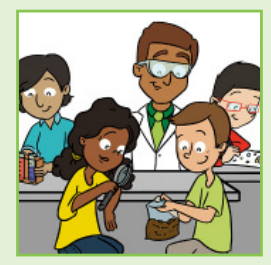

CONFLICT OF INTEREST: The authors declare that the research was conducted in the absence of any commercial or financial relationships that could be construed as a potential conflict of interest.

COPYRIGHT (c) 2021 Otte and Laufer-Meiser. This is an open-access article distributed under the terms of the Creative Commons Attribution License (CC BY). The use, distribution or reproduction in other forums is permitted, provided the original author(s) and the copyright owner(s) are credited and that the original publication in this journal is cited, in accordance with accepted academic practice. No use, distribution or reproduction is permitted which does not comply with these terms.

\section{YOUNG REVIEWERS}

\section{LICEO COCCHETTI, AGE: 15}

We are from a scientific high school in Milan, Italy, and are all 15 years old. We are attentive, lively, and reviewing this article gave us an opportunity to discover another aspect of science. When reviewing the article, we were excited to participate in the actual publication process of scientific articles.

\section{AUTHORS}

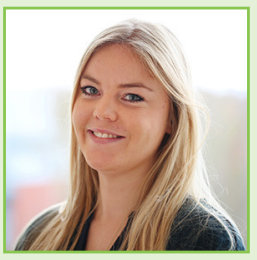

\section{JULIA M. OTTE}

I was trained in bioscience and geoscience at the University of Heidelberg (Germany) and the University of Freiburg (Germany), with a specialization in molecular biology and microbiology. In 2018, I finished my Ph.D. at the University of Tübingen (Germany) with a specialization in geomicrobiology and microbial ecology, and a focus on iron-cycling bacteria in marine sediments. From 2018 to February 2021, I have been in the HGF-MPG Group for Deep-Sea Ecology and Technology at the Alfred Wegener Institute Helmholtz Centre for Polar and Marine Research in Bremerhaven, and at the Max Planck Institute for Marine Microbiology in Bremen (Germany). As a postdoctoral researcher, I was working on the impacts of deep-sea mining in the Pacific Ocean on deep-sea microorganisms. Since March 2021, I am a researcher at the Center for Electromicrobiology in Aarhus (Denmark). *juliaotteabio.au.dk. ${ }^{\dagger}$ Center for Electromicrobiology, University of Aarhus, Aarhus, Denmark.

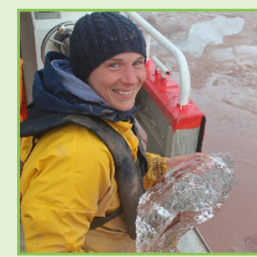

\section{KATJA LAUFER-MEISER}

I have a bachelor in biology from the University of Kiel and a Master's degree in biological oceanography from GEOMAR - Helmholtz Centre for Ocean Research in Kiel (Germany). In 2016, I finished my Ph.D. in Tübingen (Germany) in the field of geomicrobiology, studying microbial iron- cycling in marine sediments. From 2016 to 2019 I did a Postdoc in Aarhus (Denmark), investigating microbial iron-cycling in Arctic fjord sediments in Svalbard. Currently, I am a Postdoc at GEOMAR in Kiel (Germany), studying iron-cycling in Arctic fjord sediments as well as 
the microbiology of massive sulfides and hydrothermal vents along the Indian Ridge. ${ }^{\dagger}$ GEOMAR Helmholtz Center for Ocean Research Kiel, Kiel, Germany. 